\title{
Creep-Age Forming of AA7475 Aluminum Panels for Aircraft Lower Wing Skin Application
}

\author{
Diego José Inforzato ${ }^{\text {a }}$ Paulo Roberto Costa Junior ${ }^{\text {, }}$ Fernando Ferreira Fernandez, \\ Dilermando Nagle Travessa ${ }^{\mathrm{b} *}$ \\ ${ }^{a}$ Empresa Brasileira de Aeronáutica S.A. - Embraer, Av. Brigadeiro Faria Lima, 2170, \\ CEP 12227-901, São José dos Campos, SP, Brasil \\ ${ }^{\mathrm{b}}$ Departamento de Ciência e Tecnologia, Universidade Federal de São Paulo - UNIFESP, \\ Rua Talim, 330, CEP 12231-380, São José dos Campos, Brasil
}

Received: November 7, 2011; Revised: May 3, 2012

\begin{abstract}
Creep-age forming (CAF) is an interesting process for the airframe industry, as it is able to form or shape panels into smooth, but complex, curvatures. In the CAF process, the ageing cycle of the alloy is used to relax external loads imposed to the part, through creep mechanisms. Those relaxed stresses impose a new curvature to the part. At the end of the process, significant spring back (sometimes about 70\%) is observed and the success in achieving the desired form depends on how the spring back can be predicted in order to compensate it by tooling changes. Most of the applications relate to simple (non stiffened) panels. The present work deals with the CAF of aluminum panels for aircraft wing skin application. CAF was performed using vacuum-bagging autoclave technique in small scale complex shape stiffened panels, machined from an AA7475 alloy plate. An analytical reference model from the literature was employed estimate the spring back effect in such panel geometry. This model that deals with simple plates was adapted to stiffened panels using a geometric simplification, resulting in a semi-empirical model. The results demonstrate that CAF is a promising process to form stiffened panels, and the spring back can be roughly estimated through a simple model and few experiments.
\end{abstract}

Keywords: creep-age forming, spring back, semi-empirical modeling, AA7475 alloy

\section{Introduction}

Creep-age forming (CAF) is a process that combines two metallurgical phenomena, creep and precipitation hardening, in order to form a metallic part. Both phenomena are highly dependent on temperature and time. The CAF process is very interesting for the aerospace industry, mainly to form large-contoured wing skins, which presents smooth curvatures on both wing span and wing chord directions. In this case, flat panels can be machined from thinner gauge plates, resulting in cost reductions related to material and machining time. On the other hand, wings having severe dihedral angle, mainly in lower skins, can demand double curvature surfaces in narrow regions, increasing the complexity of the forming process.

Some of the examples of CAF application to form upper wing panels include ${ }^{1,2}$ the $\mathrm{B} 1 \mathrm{~B}$ and Hawk bombers, the executive jet Gufstream G-IV and the commercial Airbus jets A330 and A340, as well as the A380. This late is the biggest commercial aircraft in operation, demanding very big parts and structures and in this case, CAF process made feasible the manufacturing of the upper wing skin in lesser parts, as no aeronautical grade alloys were available in the necessary gauge to machine the curved panel in a single piece. All of these examples, however, are related to non-stiffened panels (no stringers integrated to the skin), including only localized thickness reductions optimizing

*e-mail: dilermando.travessa@unifesp.br the part weight. There are no examples of CAF application on complex stiffened panels.

In the CAF process, the part to be formed is initially forced against a tooling which has a desired curvature, through clamping mechanisms or vacuum-bagging autoclave techniques. In this first step, the forces imposed are below the yielding limit of the material. Subsequent heating starts a stress-induced deformation process that allows the material to simultaneously relax these external forces through creep mechanisms and to age by precipitation hardening. The creep mechanism introduces some permanent deformation in the material. At the final stage, the part is cooled and, as the external load is removed, part of the contour is lost due to the spring back. The magnitude of the spring back is considerable, reaching about 40 up to $70 \%$ of the imposed initial curvature ${ }^{1}$.

When comparing to other forming processes for wing panels, CAF results in parts with lower residual stresses, resulting in a better fatigue performance ${ }^{1}$. Furthermore, CAF is able to form panels into the smooth curvatures that are typical for wing applications, including double curvatures (cell shapes). The process is very reproducible. One of the challenges of the process for wing skin forming relates to the metallurgy of the alloy, which shall result in a product having good strength and toughness after the creep-age cycle. Moreover, the desired curvature can only be precisely achieved if the spring back can be anticipated, enabling 
the tooling to compensate (by over-curving) the elastic return. Modeling the spring back is a quite complex task, mainly in stiffened panels that are very stiff and have abrupt thicknesses transitions ${ }^{2}$. The material properties are transient during the process, as the precipitation hardening progresses, giving an additional complexity to the modeling task. Several attempts have been made in order to model the CAF process. Simple mathematic/phenomenological models ${ }^{3}$ or complex FEM (finite elements modeling) have been developed, mainly related to simple plates having a constant thickness. Those models usually employ equilibrium relations, as well as constitutive equations to describe the creep behavior of the material. Constitutive equations that combine creep and precipitation hardening simultaneously have been established for the AA7010 aluminum alloy ${ }^{4}$. Those equations were subsequently employed in a FEM to model thick plates with double curvature ${ }^{5}$. Using this model, the authors report that it is possible to estimate the effect of the plate thickness and process time on the spring back magnitude.

The use of CAF process to shape aircraft wing skin panels demands the use of alloys that exhibit high relaxation rates combined with high strength and toughness after the forming cycle. Fatigue and fatigue crack-growth behavior of the alloy is critical for lower skin wing panels, commonly resulting in the selection of AA2XXX series alloys, in the natural aged temper (T351). Those alloys are not suitable for creep-age forming, as in their artificial aged condition (T6 or T8 tempers), higher strength develops at the expense of the toughness and fatigue-crack growth resistance. New AA2XXX alloys with additions of $\mathrm{Li}, \mathrm{Zr}$ and SC are also being developed specifically for CAF application ${ }^{6}$. In these alloys, the addition of $\mathrm{Li}$ (from 0,5 to $1,6 \mathrm{wt} \%$ ) increases the damage tolerance of the alloy after ageing, while $\mathrm{Zr}$ and Sc stabilizes the microstructure and enhance the stress relaxation capability by creeping. The commercially available AA7475 alloy can also be a good alternative for creep-age formed lower wing skins, as it is frequently used in the overaged condition, resulting in a good combination of strength, toughness and stress corrosion cracking resistance ${ }^{7}$. In addition, the overaged temper (T73) of the AA7475 alloy shows an interesting process window for creep-age forming, as the recommended overaging procedure consists in a two step cycle of 6 to 8 hours at $121^{\circ} \mathrm{C}$ followed by 24 to 30 hours at $163{ }^{\circ} \mathrm{C}^{8,9}$. It has been observed that in the second ageing step, the relaxation rate is higher due to the dissolution of GP zones formed in the first step, nucleating the metastable $\eta$ ' that indicates the initiation of the overaging process ${ }^{10}$. Further, the relaxation rate of this alloy is appreciable when the CAF applied load is higher than $30 \%$ of the yielding strength at the temperature ${ }^{10}$. From this behavior, it can also be observed that spring back will always be present in the CAF process. Its similarity to the simple bending condition results in the presence of a neutral line that is a consequence of the equilibrium state. In the neutral line and close to it, the stresses are close to zero and consequently the CAF process will have no effect in this region.

In the presented context, the present work deals with the application of the CAF process to shape complex stiffened panels for lower wing skin applications. The CAF is performed simultaneously to the second stage of overaging of the AA7475 aluminum alloy, using a vacuum-bagging autoclave process. Further, an analytical reference model existing in the literature is used to estimate the spring back of the panels. This reference model was adapted to the case of a stiffened panel by geometric considerations and the creep-age modeling was replaced by a calibration using the final deflection of real parts, resulting in a semi-empirical model. The semi-empirical model offers a simple and cost effective form of roughly estimate the spring back, as it does not depend on complex material testing or FEM and can be calibrated by few experiments. The results are also discussed in the light of the equivalent thickness (height) approach for the model and its use to predict the spring back.

\section{Experimental Setup}

\subsection{Materials and forming process}

Three conceptual small scale parts, measuring $600 \times 300 \mathrm{~mm}$ were flat machined from a $50.8 \mathrm{~mm}$ thick AA7475-T7351 aluminum plate. These panels represent the root region of typical lower wing panel of medium size regional jets, having 11 longitudinal blade stiffeners along the $y$ direction and one transversal along the $\mathrm{x}$ direction, in the root region $(\mathrm{y}=0)$, see Figure 1 . The skin, longitudinal and transversal stiffeners have variable thickness, as observed in the same figure. Additionally, 5 of the longitudinal stiffeners also have a decreasing height, disappearing at $y=210 \mathrm{~mm}$. These geometric characteristics make the CAF process exceptionally complex in these panels. Chemical composition and other characteristics of the plate met SAE AMS4202D specification ${ }^{11}$. Before machining, the plate was solution heat treated at $480{ }^{\circ} \mathrm{C}$ for 3 hours, water quenched and artificially aged at $121^{\circ} \mathrm{C}$ for 6 hours, in order to accomplish the first step of the AA7475 overaging 9 .

For the autoclave CAF process, a curved tooling was manufactured in aluminum, as shown in Figure 2. This tooling had a curved surface with a constant radius of $3750 \mathrm{~mm}$ along the $\mathrm{x}$ direction. This curvature was estimated considering a spring back of about $70 \%{ }^{5}$, to result in a final curvature of about $1120 \mathrm{~mm}$ (typical for medium size regional jets). The flat panel was positioned on the top of the tooling and a vacuum bag was mounted, see Figure 3. The objective of the vacuum bag is to eliminate the air between the work piece and the tooling, resulting in a perfect contact between then, when the autoclave pressure is applied. The autoclave CAF process was performed under a pressure of $7 \mathrm{~atm}$ (about $710 \mathrm{kPa}$ ) at $163^{\circ} \mathrm{C}$ for 24 hours, corresponding to the second stage of the AA7475 overaging, reaching the final temper T73. Rockwell B hardness testing was performed in the formed parts in order to confirm that the ageing cycle of the alloy was accomplished. The final deflection was measured in the three conceptual parts using a 3D scanning laser tracking equipment. Five sections of the part (plane $\mathrm{x}-\mathrm{z}$ ), including both extremities, were used to check the part deflection, see the Figure 4. From the deflection measurement of each section, the radius and the 


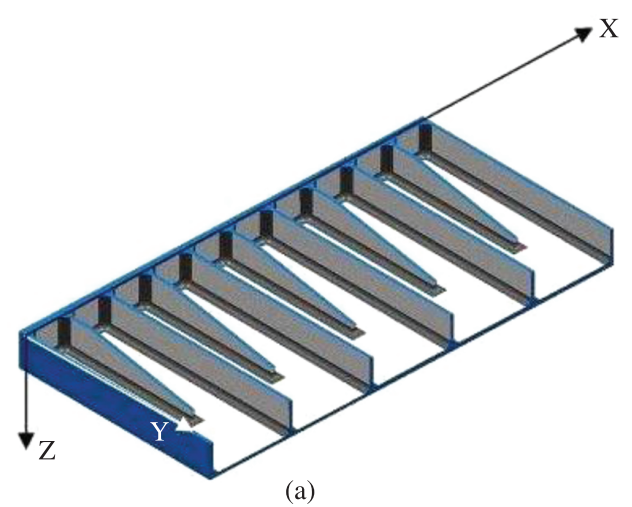

(a)

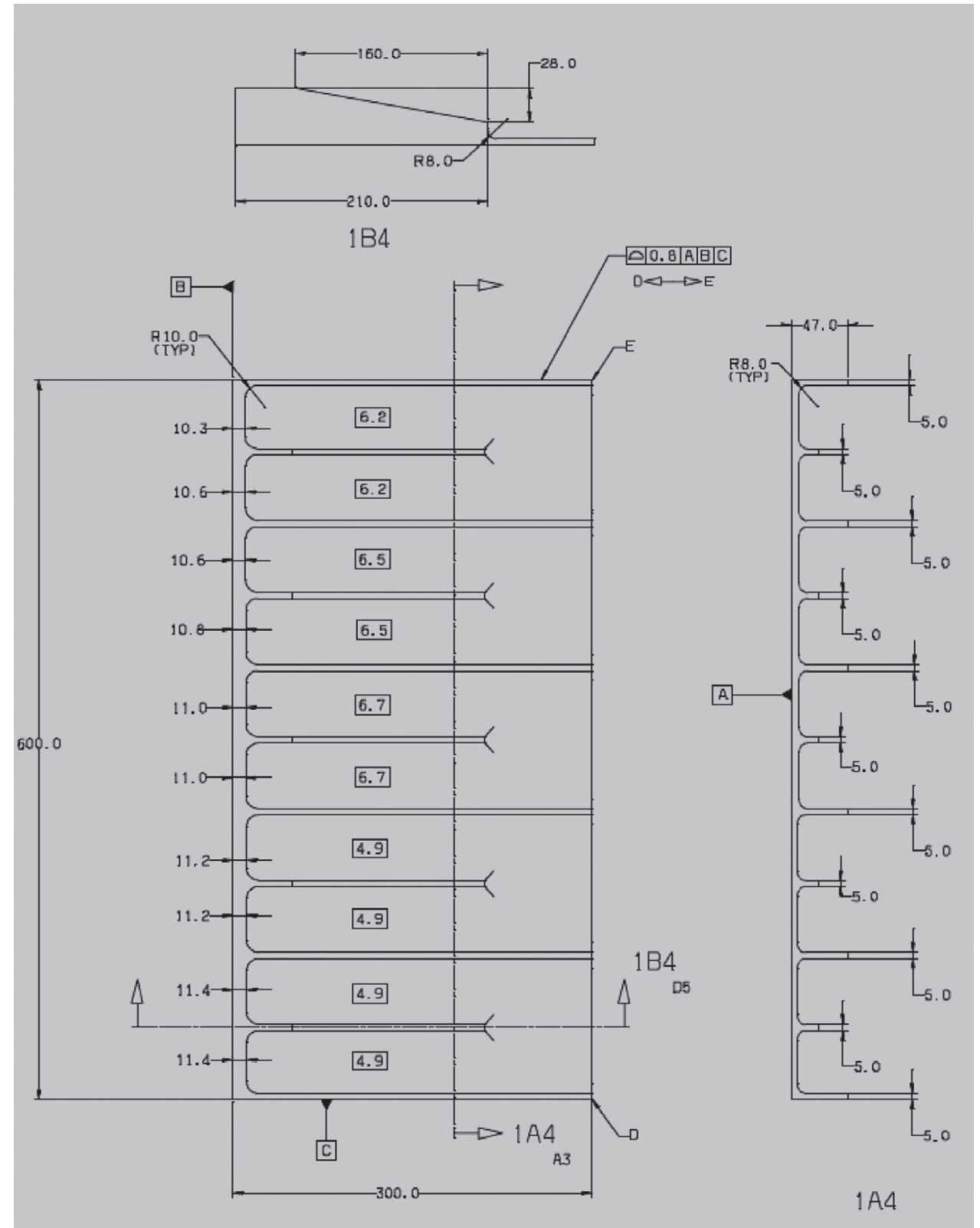

(b)

Figure 1. Conceptual stiffened panel manufactured for creep-age forming evaluation: a) Isometric view; b) Details of the project (dimensions in millimeters). 
curvature of the panels were calculated using the simple following relations (Equations 1 and 2):

$r=\frac{(L / 2)^{2}+\delta^{2}}{2 \times \delta}$

$r=\frac{1}{k_{11}}$

where $r$ is the radius after the forming, $\mathrm{L}$ is the part width (along the $\mathrm{x}$ direction), $\delta$ is the measured deflection and $\mathrm{k}_{11}$

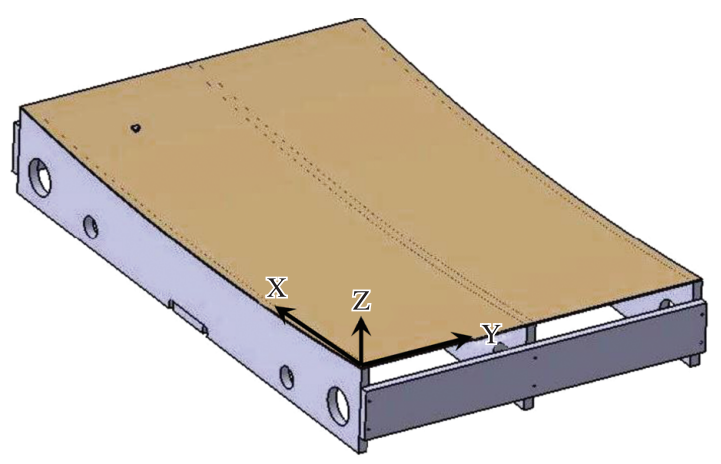

Figure 2. Tooling manufactured for the autoclave creep-age forming process.

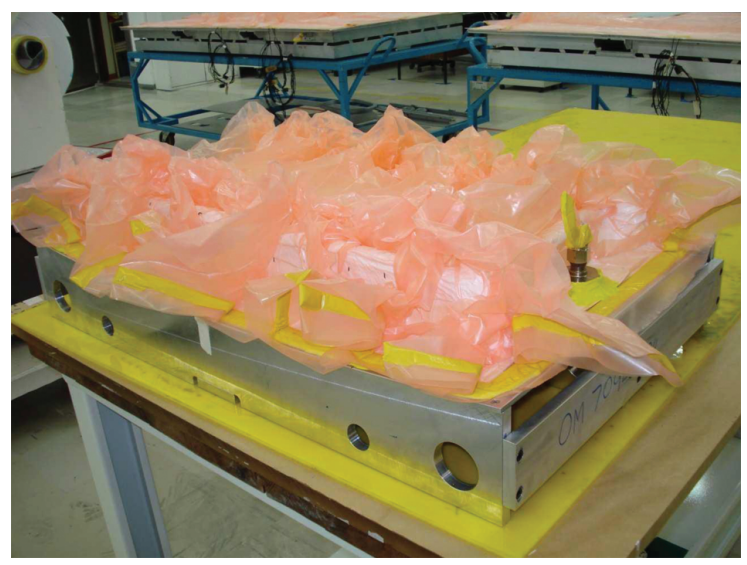

Figure 3. Vacuum bag assembling, just before the autoclave forming.

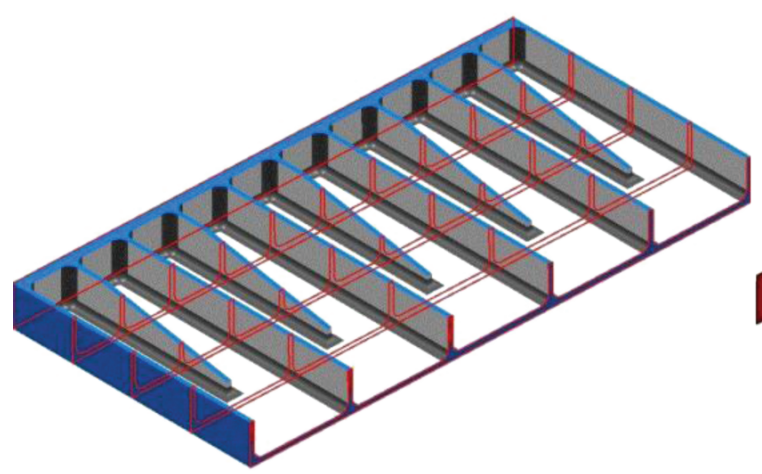

is the section curvature. The spring back was obtained comparing the curvature of the part in these five different sections with the tooling curvature.

\subsection{Spring back modeling and final deflection calculation}

Spring back and final deflection of the formed part were estimated using an analytical reference model developed for simple non-stiffened plates with constant thickness ${ }^{4,5}$. This reference model includes a classical plate bending theory and creep-age constitutive equations to describe the material behavior during the CAF process. In order to apply this model to a stiffened panel, an equivalent thickness concept was employed. According to this concept, any complex stiffened section of the panel can be simplified to a plate having an equivalent thickness or height, resulting in the same moment of inertia, as follows (Equations 3 and 4):

$$
\begin{aligned}
& M^{y}=\frac{L \times h^{3}}{12} \\
& h_{e q}=\sqrt[3]{\frac{12 \times M^{y}}{L}}
\end{aligned}
$$

where $\mathrm{M}^{\mathrm{y}}$ is the moment of inertia of each cross section of the panel and $\mathrm{h}_{\mathrm{eq}}$ is the equivelent thickness of a simple plate, parametrized by the moment of inertia of the correspondent cross section. Using the calculated $h_{\text {eq }}$ value, the bending stifness modulus (D) and the initial and final bending moment ( $\mathrm{M}^{0}{ }_{11}$ and $\mathrm{M}_{11}$ respectivelly) were calculated using the following expressions ${ }^{5}$ (Equations 5-9):

$$
\begin{aligned}
& D=\frac{E \times h_{e q}^{3}}{12} \\
& M_{11}^{0}=D \times k_{11}^{0} \\
& M_{11}=D \times k_{11} \\
& k_{11}^{0}=\frac{1}{r^{0}} \\
& k_{11}=\frac{1}{r^{f}}
\end{aligned}
$$

where $\mathrm{E}$ is the elastic modulus of the alloy (70,3 GPa), $\mathrm{r}^{0}$ and $\mathrm{r}^{\mathrm{f}}$ are the initial and final radius of the panel and

Figure 4. Cross sections for deflection evaluation, after forming.

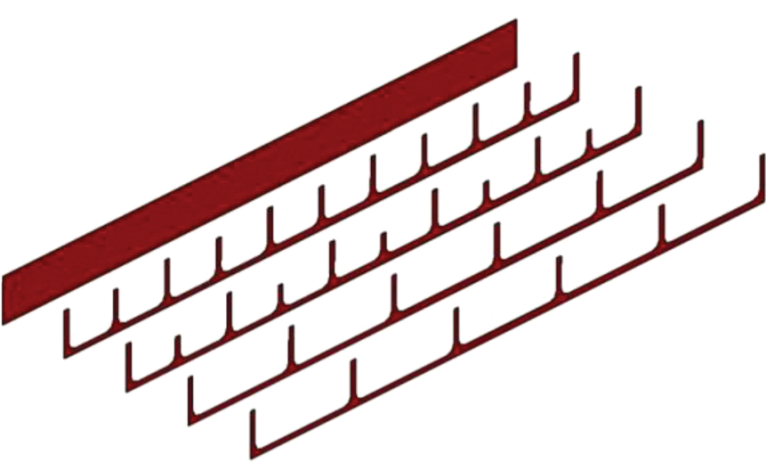


$\mathrm{k}^{0}{ }_{11}$ and $\mathrm{k}_{11}$ are the inverse of the inicial curvature (curvature of the tooling) and final curvature respectivelly. $\mathbf{M}^{0}{ }_{11}$ and $\mathbf{M}_{11}$ represents the bending moment for a specific geometry that results in the initial curvature (equal to the tooling curvature) and in the final curvature (after CAF). This approach is valid only if the autoclave pressure and the vaccuum bagging technique are sufficient to push the part in full contact with the tooling. As the radius of the tooling was $3750 \mathrm{~mm}$, the value of $\mathrm{k}^{0}{ }_{11}$ was calculated as $2,67 \times 10^{-4} \mathrm{~mm}^{-1}$.

In the reference model, the final curvature $r_{\mathrm{f}}$ is obtained, as already mentioned, using complex creep-age constitutive equations relating simultaneously plasticity, hardening, creep and recovery. In the present work, the main objective of modelling was to simpify the geometric characteristics of a stiffened panel in order to apply the analytical classical plate bending theory. Consequently, creep-age modelling was not employed in the present work, and the $\mathrm{M}_{11}$ was obtained from the final curvature $\mathrm{k}_{11}$ of the formed parts. This approach results in a semi-empirical model to predict the spring back of complex stiffened panels based only in the classical plate bending theory and in few experiments. The initial and final deflection, as well as the spring back, were calculated by the following expressions (Equations 10-12):

$\delta^{0}=\frac{M_{11}^{0}}{2 \times D} \times\left(\frac{L}{2}\right)^{2}$

$\delta=\frac{M_{11}}{2 \times D} \times\left(\frac{L}{2}\right)^{2}$

$s b(\%)=100 \times\left(1-\frac{\delta}{\delta^{0}}\right)$

where $\delta^{0}$ and $\delta$ are the initial and final deflections and sb is the spring back.

\section{Results and Discussion}

The creep-age forming process using the vacuum-bagging autoclave technique successfully formed the three conceptual parts, under the experimental conditions employed in the present work. Hardness testing performed after forming resulted in values between 78 and $80 \mathrm{HRB}$, confirming that the overaged condition was attained ${ }^{12}$. The Figure 5 shows the deflection measurements of one of the formed parts, which showed to be very similar to the other parts and confirming that CAF is a highly reproducible process (see Table 1 captions). In these measurements, a laser tracking equipment was employed, scanning the outer surface of the panel (opposite to the stiffeners) in 60 points. The $x-y$ coordinates of these 60 points refers to fixed values of $\mathrm{x}$ from 0 to $600 \mathrm{~mm}$ in intervals of $54.5 \mathrm{~mm}$, and $\mathrm{y}=0$, $55,150,240$ and $300 \mathrm{~mm}$. The laser tracking readings were compared to the CATIA ${ }^{\circledR} 3 \mathrm{D}$ flat panel model, taking the coordinate $\mathrm{x}=0$ and $\mathrm{y}=300$ as the reference point. It can be observed that at the edges of the part at coordinates $(\mathrm{x}, \mathrm{y})=(0,0),(600,0),(600,300)$, the deflections are not zero, opposite to the expected. This result can be related to the machining tolerances of the machined flat panel (about $\pm 0.2 \mathrm{~mm}$ ) or even to a panel twisting during the autoclave forming process. However, as the deflection readings are very small, these measurements were not considered in the average radius calculation for all of the five sections, presented in Table 1. From Table 1, it is evident that for fixed values of $\mathrm{x}$ the deflection resulting from the CAF increases as the skin and stringers thicknesses decrease from the tip to the root region of the panel. The deflections are particularly small in the section $y=0$ due the presence of a very stiff reinforcing element imposing restrictions to the panel bending, supporting the idea that forming such complex parts to a desired contour is a difficult task. The

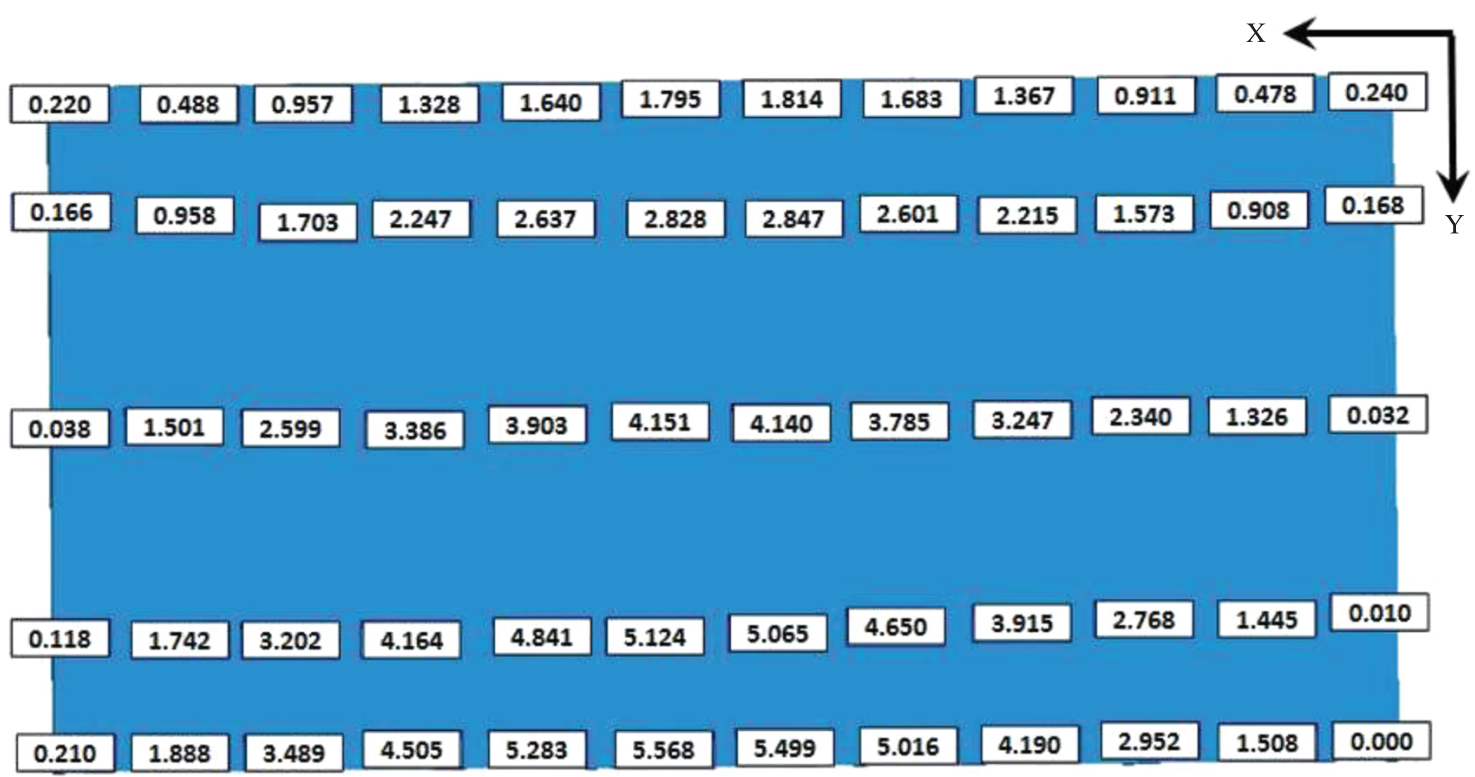

Figure 5. Deflection measurements performed by laser tracking over the external surface of one of the conceptual parts. Negative readings refer to overformed regions and the dimensions are in millimeters. 
Table 2 shows the calculated radius and curvature for the five different sections of the part, based on the mean value of the three parts, considering only the highest deflection that is in the central region of the part $(x=327 \mathrm{~mm})$. In the same table, the calculated moment of inertia of the sections, based in the concept of equivalent thickness as discussed in section 2.2, are also presented. It can be observed that the moment of inertia of the first section $(y=0)$ is about 5 to 10 times higher than of the other sections, resulting in the smaller curvature of the part.

The spring back calculation was performed, as already mentioned, based on a simplification of a reference model ${ }^{5}$ that employs the classical plate bending theory, but using the concept of equivalent height to simplify the geometry of complex stiffened panels to simple plates. Table 3 shows the parameters used to calculate the spring back using this simplification modeling. The spring back measured directly in the formed part is also presented. It can be observed that the calculated spring back was very close to the average values measured in the parts. Although the final deflection of the formed panels has been used to calculate the bending moment that results in the final curvature, the convergence of the modeling result demonstrates that the concept of equivalent height is valid. Further, this simplified model, that does not take into account the creep-precipitation hardening phenomena, seems to be very promising as a first approach for tooling geometry and using few small scale conceptual parts. In the present work, for instance, it has been shown that the spring back is different in different sections of the part (due to differences in stiffness). Consequently, the tooling should have different curvatures along the $y$ direction, in order to reach a final part with the constant desired curvature. The present results address for tooling corrections in each section, varying from $\sim 86 \%$ in section 1 to $\sim 55 \%$ in section 5 . For parts made from the same material and using the same forming parameters, one can predict using this simple semi-analytical modeling with a reasonable precision, the behavior of panels with different geometries.

Table 1. Average deflection of the three conceptual parts in 50 of the reading points (points related to $\mathrm{x}=0$ and $\mathrm{x}=600 \mathrm{~mm}$ were not considered. The dimensions are in millimeters ( $\pm 5 \%$ maximum).

\begin{tabular}{|c|c|c|c|c|c|}
\hline$X$ coordinate & $\begin{array}{c}\text { Section } 1 \\
y=0\end{array}$ & $\begin{array}{c}\text { Section } 2 \\
y=55\end{array}$ & $\begin{array}{c}\text { Section } 3 \\
\mathbf{y}=\mathbf{1 5 0}\end{array}$ & $\begin{array}{c}\text { Section } 4 \\
y=240\end{array}$ & $\begin{array}{c}\text { Section } 5 \\
\mathbf{y}=\mathbf{3 0 0}\end{array}$ \\
\hline$x=54.5$ & 0.48 & 1.08 & 1.56 & 1.74 & 1.84 \\
\hline$x=109.0$ & 0.93 & 1.78 & 2.58 & 3.08 & 3.39 \\
\hline$x=163.5$ & 1.30 & 2.33 & 3.30 & 3.99 & 4.48 \\
\hline$x=218.0$ & 1.59 & 2.69 & 3.78 & 4.64 & 5.24 \\
\hline$x=272.5$ & 1.73 & 2.89 & 4.03 & 4.92 & 5.52 \\
\hline$x=327.0$ & 1.73 & 2.91 & 4.02 & 4.88 & 5.48 \\
\hline$x=381.5$ & 1.58 & 2.69 & 3.73 & 4.53 & 5.09 \\
\hline$x=436.0$ & 1.30 & 2.34 & 3.24 & 3.87 & 4.29 \\
\hline$x=490.5$ & 0.88 & 1.76 & 2.46 & 2.91 & 3.20 \\
\hline$x=545.5$ & 0.46 & 1.07 & 1.49 & 1.60 & 1.63 \\
\hline
\end{tabular}

Table 2. Calculated radius and curvature of the formed parts, based on the deflection in the middle of the part $(\mathrm{x}=327 \mathrm{~mm})$.

\begin{tabular}{lccccc}
\hline & $\begin{array}{c}\text { Section } \mathbf{1} \\
\mathbf{y = 0}\end{array}$ & $\begin{array}{c}\text { Section 2 } \\
\mathbf{y = 5 5}\end{array}$ & $\begin{array}{c}\text { Section 3 } \\
\mathbf{y}=\mathbf{1 5 0}\end{array}$ & $\begin{array}{c}\text { Section 4 } \\
\mathbf{y}=\mathbf{2 4 0}\end{array}$ & $\begin{array}{c}\text { Section 5 } \\
\mathbf{y}=\mathbf{3 0 0}\end{array}$ \\
\hline Measured deflection $\delta$ in $\mathrm{x}=327 \mathrm{~mm}(\mathrm{~mm})$ & 1.73 & 2.91 & 4.02 & 4.88 & 5.48 \\
Calculated radius $\mathrm{r}_{\mathrm{f}}$ of formed part $(\mathrm{mm}) \times 10^{4}$ & 2.60 & 1.55 & 1.12 & 0.92 & 0.82 \\
Calculated curvature $\mathrm{k}_{11}$ of formed part $\left(\mathrm{mm}^{-1}\right) \times 10^{-5}$ & 3.84 & 6.46 & 8.94 & 10.84 & 12.18 \\
Equivalent height $\mathrm{h}_{\mathrm{eq}}(\mathrm{mm})$ & 47.00 & 26.89 & 24.73 & 23.96 & 23.96 \\
Calculated moment of inertia $\mathrm{M}^{\mathrm{y}}\left(\mathrm{mm}^{4}\right) \times 10^{5}$ & 51.9 & 9.72 & 7.56 & 6.89 & 6.88 \\
\hline
\end{tabular}

Table 3. Semi-empirical model parameters used to calculate the spring back. The spring back measured directly in the formed parts is also presented.

\begin{tabular}{|c|c|c|c|c|c|}
\hline & $\begin{array}{c}\text { Section } 1 \\
\mathbf{y}=\mathbf{0}\end{array}$ & $\begin{array}{c}\text { Section } 2 \\
y=55\end{array}$ & $\begin{array}{c}\text { Section } 3 \\
y=150\end{array}$ & $\begin{array}{c}\text { Section } 4 \\
y=240\end{array}$ & $\begin{array}{c}\text { Section } 5 \\
\mathbf{y}=\mathbf{3 0 0}\end{array}$ \\
\hline Stiffness bending modulus (D) $\left(\mathrm{MPa} \mathrm{mm} \mathrm{mm}^{3}\right) \times 10^{7}$ & 60.8 & 13.9 & 0.85 & 0.81 & 0.81 \\
\hline Initial bending moment $\left(\mathrm{M}_{11}^{0}\right)(\mathrm{N}) \times 10^{4}$ & 16.2 & 3.04 & 2.36 & 2.15 & 2.15 \\
\hline Final bending moment $\left(\mathrm{M}_{11}\right)(\mathrm{N}) \times 10^{3}$ & 23.3 & 7.36 & 7.92 & 8.73 & 9.81 \\
\hline Initial deflection $\delta_{0}(\mathrm{~mm})$ (due to tooling) & 12.0 & 12.0 & 12.0 & 12.0 & 12.0 \\
\hline Final deflection $\delta_{\mathrm{f}}(\mathrm{mm})$ (measured in the parts) & 1.73 & 2.91 & 4.02 & 4.88 & 5.48 \\
\hline Spring back sb calculated by the model (\%) & 85.6 & 75.8 & 66.5 & 59.3 & 54.3 \\
\hline Spring back sb measured in the formed parts $(\% \pm 1 \%$ max.) & 86.9 & 75.4 & 65.5 & 59.2 & 55.1 \\
\hline
\end{tabular}




\section{Conclusions}

Based on the results obtained in the present work, the following conclusions can be presented:

- The simplification of the reference model, including the equivalent height concept was valid for the AA7475 aluminum alloy, under the forming conditions employed in this work. The classical plate bending theory could be applied and the deflections experimentally measured could adequately calibrate the semi-empirical model;

- The spring back was observed to be strongly dependent on the stiffness and moment of inertia of each section, being higher as higher the stiffness;

\section{References}

1. Holman MC. Autoclave age forming large aluminum aircraft panels. Journal of Mechanical Working Technology. 1989; 20:477-488. http://dx.doi. org/10.1016/0378-3804(89)90055-7

2. Brewer H. Age forming integrally stiffened aluminum aerospace structures in anautoclave. In Proceedings of the Aircraft Design, Systems and Operations Conference; 1989; Seattle. Edimet Spa; 1989. p. 6-8.

3. Narimetla SP, Peddieston J and Buchanan GR. A simple unified age forming model. Materials Research Communications. 2000; 27:631-636. http://dx.doi.org/10.1016/ S0093-6413(00)00139-7

4. Ho KC, Lin J and Dean TA. Constitutive modelling of primary creep for age forming an aluminium alloy. Journal of Materials Processing Technology. 2004; 153-154:122-127. http://dx.doi. org/10.1016/j.jmatprotec.2004.04.304

5. Jeunechamps PP, Ho KC, Lin J, Ponthot JP and Dean TA. A closed form technique to predict springback in creep age-forming. International Journal of Mechanical Sciences. 2006; 48:621-629. http://dx.doi.org/10.1016/j. ijmecsci.2006.01.005

6. Starink MJ, Gao N, Kamp N, Wang SC, Pitcher PD and Sinclair I. Relations between microstructure, precipitation, age-formability and damage tolerance of $\mathrm{Al}-\mathrm{Cu}-\mathrm{Mg}-\mathrm{Li}$

- This simplified model can be used to estimate the spring back of panels having different reinforcement geometries, if a trial is performed using few conceptual panels from the same material and under the same process parameters; and

- In the present work, it was observed that the creep-age forming process can be employed to form complex stiffened panels. The spring back estimation showed that tooling should have different curvatures along the y direction, in order to result in a homogeneous curvature.

(Mn, Zr, Sc) alloys for age forming. Materials Science and Engineering. 2006; A48:241-249.

7. Oliveira Junior AF, De Barros MC, Cardoso KR and Travessa DN. The effect of RRA on the strength and SCC resistance on AA7050 and AA7150 aluminium alloys. Materials Science \& Engineering. 2004; A379:321-326.

8. Society of Automobile Engineers - SAE. AMS 2770H: Heat Treatment of Wrought Aluminum Alloy Parts. SAE International; 2006.

9. Society of Automobile Engineers - SAE. AMS 2772E: Heat Treatment of Aluminum Alloy Raw Materials. SAE International; 2008.

10. Robey RF, Prangnell PB and Dif RA. A Comparison of the Stress Relaxation Behaviour of Three Aluminium Aerospace Alloys for use in Age-Forming Applications. Materials Forum. 2004; 28:132-138.

11. Society of Automobile Engineers - SAE. AMS 4202D: Aluminum Alloy Plate $5.7 \mathrm{Zn}-2.2 \mathrm{Mg}-1.6 \mathrm{Cu}-0.22 \mathrm{Cr}$ (7475-T7351) Solution Heat Treated, Stress Relieved by Stretching, and Precipitation Heat Treated - UNS A97475. SAE International; 2005.

12. Society of Automobile Engineers - SAE. AMS 2658C: Hardness and Conductivity Inspection of Wrought Aluminum Alloy Parts. SAE International; 2009. 